Revista de
Economild
Contemporâned

\title{
MAIS DO QUE RELAÇÃO UNIVERSIDADE EMPRESA: UMA ANÁLISE DAS FONTES DE CONHECIMENTO ESPECIALIZADO PARA INOVAÇÃO NA ARGENTINA, A PARTIR DE MICRODADOS*
}

\begin{abstract}
Pablo F. Bittencourt ${ }^{a}$
Diogo Signor ${ }^{b}$

Eva Yamila da Silva Catela ${ }^{c}$

Márcia S. Rapini ${ }^{d}$

aProfessor do Programa de Pós-Graduação em Economia (PPGEco) e do Departamento de Economia e de Relações Internacionais da Universidade Federal de Santa Catarina (UFSC).

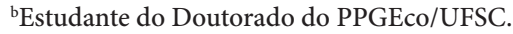

'Professora do PPGEco e do Departamento de Economia e de Relações Internacionais da UFSC. dProfessora Adjunta da Faculdade de Administração e Ciências Econômicas (FACE) e do Centro de Desenvolvimento e Planejamento Regional (CEDEPLAR) da Universidade Federal de Minas Gerais (UFMG).
\end{abstract}

Artigo recebido em 28/10/2016 e aprovado em 13/06/2017.

RESUMO: A complexidade do processo inovativo exige que as firmas colaborem com um conjunto de instituições públicas e privadas, assim como outras firmas, para construir e utilizar conhecimentos especializados, inerentes ao processo de inovação. Utilizando um modelo probit ordenado e microdados de 3.691 firmas argentinas, este trabalho tem como objetivo investigar e analisar a relação entre características chave das firmas do setor industrial de um país em desenvolvimento e a rede de fornecedores

* Os autores agradecem ao parecerista anônimo da Revista de Economia Contemporânea. Os eventuais erros e omissões, no entanto, são de responsabilidade dos autores.

Correspondência para: Pablo F. Bittencourt

Contato: pablofelipe.bittencourt@gmail.com 
de conhecimentos especializados com a qual as firmas estabelecem suas redes. Os resultados apontam que o nível de abertura da empresa, sua capacidade de absorção, o engajamento no desenvolvimento de inovações de alto impacto, além da forma como as subsidiárias de multinacionais interagem com as matrizes e a atuação em mercados de exportação, são determinantes das redes formadas pelas firmas argentinas em processos de inovação.

PALAVRAS-CHAVE: universidades; institutos de pesquisa; consultores; survey de inovação; Argentina.

CLASSIFICAÇÃO JEL: C35, D22, L25. 


\title{
MORE THAN THE UNIVERSITY INDUSTRY RELATIONSHIP: AN ANALYSIS OF SOURCES OF SPECIALIZED KNOWLEDGE FOR INNOVATION IN ARGENTINA, FROM MICRODATA
}

\begin{abstract}
The complexity of the innovation process requires firms to collaborate with a group of public and private institutions, as well as other firms, which are outside of its organization to build and use expertise inherent to this process. Using an ordered probit model and microdata of nearly 4,000 Argentine firms, this paper aims to study the relationship between the key characteristics of firms in the industrial sector of a developing country and the network of specialized knowledge providers with which it relates. The results show that the firm's level of openness, its absorption capacity, the engaging in the development of high impact innovations, how multinational subsidiaries firms interact with its parent company and the operation in export markets are determinants to the network formed by Argentine firms in their innovation processes.
\end{abstract}

KEYWORDS: universities; research institutes; consultancies; innovation survey; Argentina. 


\section{INTRODUÇÃO}

A complexidade do processo inovativo, num contexto de mercados globais e de crescente concorrência, leva a um importante crescimento das redes externas à firma como fonte de conhecimentos especializados. As empresas dificilmente conseguem inovar sozinhas e a estratégia de cooperação, que resulta em estruturas de redes, é uma das formas de reduzir o risco e o custo, favorecendo a troca de informação e de conhecimento, e com isto a integração de competências tecnológicas, organizacionais e produtivas (BRITTO, 2016). A cooperação com diversos e distintos agentes do Sistema de Inovação também é uma forma de intensificar o processo de inovação.

Todavia, a cooperação com agentes externos depende de atributos internos às empresas, muitas vezes construídos ao longo do tempo através de processos de aprendizagem. A literatura atribui importância ao que se denomina "capacidade de absorção", como sendo a capacidade de identificar o conhecimento externo relevante, assimilar e transformar em inovação. A construção desta capacidade internamente é fundamental para que a empresa possa se beneficiar das interações em rede.

O objetivo deste trabalho é investigar e analisar a relação entre característicaschave das firmas do setor industrial de um país em desenvolvimento e a rede de fornecedores de conhecimentos especializados com a qual se relaciona. Para isto, utilizam-se os microdados da pesquisa "Encuesta Nacional de Dinámica de Empleo e Innovación” (ENDEI) ${ }^{1}$, que conta com informação para o período de 2010 a 2012 de uma amostra estratificada por setor e tamanho de 3.691 firmas da indústria de transformação argentina, de um universo de 15.368 firmas.

Dado este objetivo, utilizar-se-á um modelo probit ordenado que hierarquiza o número de vínculos com universidades, instituições de ciência e tecnologia e consultores especializados, realizados por empresas argentinas em seus processos de inovação. $\mathrm{O}$ modelo aponta a probabilidade de ocorrência de um ou mais dos vínculos com fornecedores especializados de conhecimentos a partir de suas capacidades de absorção (COHEN e LEVINTHAL, 1990; LANDRY et al., 2002), o engajamento em inovações de alto impacto (CALOGHIROU et al., 2004; TÖDTLING et al., 2009; FORÉS e CAMISÓN, 2016) a forma de interação com a matriz (ARIFFIN e BELL, 1999; MARIN e BELL, 2006) e a inserção em mercados mais complexos e sofisticados (ALVAREZ, 2009).

\footnotetext{
1 Publicada em 2015, trata-se de uma pesquisa conjunta dos Ministérios de Ciência, Tecnologia e Inovação Produtiva, o de Trabalho, Emprego e Seguridade Social da Argentina, junto ao Banco Interamericano de Desenvolvimento (BID).
} 
Os resultados do modelo apontam que a conformação de vínculos com instituições provedoras de conhecimento especializado das empresas argentinas pode ser caracterizado por três fatos: (i) a vinculação é um fenômeno raro, dado que em quase todos os setores a maioria das empresas não faz nenhum tipo de vínculo; (ii) em termos absolutos, os setores tradicionais como alimentos, produtos têxteis, confecções, madeira e produtos de borracha e plástico, são os que apresentam firmas com maior número de vínculos; e (iii) em termos proporcionais, os setores de alta tecnologia possuem as empresas que mais criam vínculos.

Dado este objetivo, o trabalho encontra-se estruturado da seguinte forma. Na seção dois é apresentada a revisão teórica e bibliográfica que estabelece a relação entre inovação e redes, assim como as hipóteses que contextualizam a pesquisa empírica. A terceira seção contém uma breve explicação da fonte de dados utilizada, das estatísticas descritivas dos microdados e da estratégia econométrica utilizada. Na seção quatro, os resultados dos modelos são discutidos. Fecha-se o trabalho na seção cinco, com os comentários finais.

\section{REVISÃO TEÓRICA E HIPÓTESES}

\subsection{REVISÃO TEÓRICA: INOVAÇÃO E REDES}

A natureza interconectada e interdependente da inovação está fortemente relatada na literatura de sistemas de inovação (NELSON, 1993; LUNDVAL, 2007). A empresa não consegue inovar sozinha. O conhecimento necessário para o processo de inovação é cada vez mais multidisciplinar, exigindo acessar o conhecimento também gerado fora da empresa. Inovar implica a capacidade de reconhecer e assimilar o valor das informações externas à firma. Daí, o crescimento das redes de inovação nas últimas décadas, estruturas resultantes das estratégias de cooperação das empresas com outros agentes do SI. As redes envolvem a combinação de competências da firma inovadora com as de universidades, institutos de pesquisa, consultores, clientes, fornecedores e concorrentes.

Para o objetivo específico da inovação, a cooperação tecnológica favorece a criação e circulação de informação e de conhecimento, que amplia o aprendizado coletivo e, portanto, o potencial de inovação dos participantes. Em resumo, pode-se dizer que as redes envolvem a combinação de competências da empresa inovadora com a de outros agentes que podem estar na própria cadeia produtiva (clientes, fornecedores e concorrentes) ou externa à ela nas instituições que geram conhecimento (universidades, institutos de pesquisa). 
Os benefícios ou vantagens da articulação em redes variam de acordo com a natureza da cooperação, mas, no geral, estão relacionados ao que se denomina de acesso a economias externas, podendo abranger: aumento das economias de escala e de escopo, ampliação dos mercados, aceleração do processo de inovação e acesso a competências críticas (BRITO, 2017). Em relação a este último aspecto, pode-se destacar que as redes permitem que as empresas se especializem em suas competências centrais, preservando a abrangência de sua atuação no mercado, ademais de serem uma oportunidade para a aglutinação de competências.

Porém, para que a estratégia de cooperação seja eficaz para favorecer inovação nas empresas, é fundamental que as mesmas tenham o que Cohen e Levinthal (1990) denominaram "capacidade de absorção". Esta capacidade é definida em função da habilidade da firma para reconhecer o valor da informação externa, assimilá-la e aplicá-la a fins comerciais. Basicamente, essa habilidade pode envolver conhecimentos gerados nos departamentos formais de $\mathrm{P} \& \mathrm{D}$, no ambiente de produção da firma ou simplesmente ser derivada dos indivíduos que dela fazem parte.

Trabalhadores com maiores níveis de qualificação possuem uma maior facilidade para acessar, assimilar e utilizar conhecimentos externos, aumentando a base de conhecimento da empresa (ZAHRA e GEORGE, 2002; COHEN e LEVINTHAL, 1990). Trabalhadores com ensino superior agregam técnicas e conhecimentos atualizados (KLEVORICK et al., 1995) e facilitam acessar redes externas de conhecimento (MANGEMATIN e NESTA, 1999; CLAUSEN, 2013), atuando como gatekeepers, monitorando, traduzindo e transferindo as informações externas para as empresas (COHEN e LEVINTHAL, 1990).

Estudos também apontam que a capacidade de absorção (CA) é ampliada quando estão presentes os dois modos de aprendizagem: um cujos conhecimentos tácitos são mais intensivos (DOI mode, que inclui conhecimentos adquiridos mediante a aprendizagem by doing, using e interacting ${ }^{2}$ ) e outro cujos conhecimentos codificados são mais intensos (STI mode, que inclui atividades de P\&D e a interação com universidades e centros de pesquisa) (JENSEN et al., 2007). Empresas com maiores CA conseguem explorar o conhecimento externo de uma forma mais eficiente aumentando seu desempenho inovativo (ESCRIBANO et al., 2009). Ebers e Maurer (2014) e Murovec e Prodan (2009) identificaram empiricamente que empresas com maior CA possuem mais probabilidade de inovar em produto e em processo. Em trabalho recente, Laursen e Salter (2014) e Ince et al. (2016) comprovam o impacto positivo da capacidade de absorção na inovação.

\footnotetext{
2 Inclui a interação com fornecedores, clientes e concorrentes.
} 
O crescimento das redes e das estratégias cooperativas por um lado, aliado ao aumento da importância de inúmeras fontes de conhecimento, caracterizando um modelo aberto de gestão da inovação, foi, por Chesbrough (2006), denominado “inovação aberta”. Atualmente, o conjunto de conhecimentos potencialmente relevantes à inovação, especialmente as de maior impacto, está distribuído em diversos locais, o que torna necessário manter um modelo de gestão da inovação capaz de reconhecer o valor do que está sendo realizado fora da empresa. Em perspectiva histórica, pode-se afirmar que se trata de um momento de transição de formas de inovar, ou melhor, de modelos de inovação, mais fechados para outros mais abertos ${ }^{3}$.

O relevante a reter é que a interação com agentes externos é mais relevante para empresas que adotam o modelo aberto (CHESBROUGHT, 2006). Não obstante, Laursen e Salter (2006) apesar de reconhecerem os benefícios da variedade de conhecimentos típicos de modelos mais abertos, ressaltam que o grau de abertura deve ser ponderado pelos custos associados a mesma. Como se trata de um processo que pode ser caro, demorado e trabalhoso, um excesso de esforços de abertura pode afetar negativamente a performance inovadora, o que reforça a importância do gerenciamento dos recursos da firma destinados à inovação. Nesse sentido, Laursen (2012) destacou ainda um "paradoxo da variedade", ao notar que firmas de indústrias marcadas por rápido desenvolvimento tecnológico tendem a utilizar diferentes estratégias de busca de conhecimentos, mas acabam revelando perfis tecnológicos similares.

A literatura também aponta diferença em termos dos parceiros na cooperação. As universidades e os institutos de pesquisa há muito são reconhecidos como importantes fontes de oportunidades tecnológicas, através do desenvolvimento de ciência básica e aplicada, além do treinamento de mão de obra qualificada para trabalhar nas empresas (KLEVORICK et al., 1995). Em países em desenvolvimento, essas instituições desempenham papel decisivo, não apenas substituindo e complementando o $\mathrm{P} \& \mathrm{D}$ realizado pelas empresas, como também conectando o Sistema de Inovação do qual fazem parte, com fontes globais de conhecimento, funcionando como "antenas" que captam os avanços na fronteira tecnológica (ALBUQUERQUE, 1999). Não obstante, Qiu, Liu e Gao (2017), tenham mostrado que os benefícios da interação global costumam limitar-se às regiões mais desenvolvidas dos países em desenvolvimento. Tether e Tajar (2008) apresentam os consultores como fontes de conhecimento do mesmo "tipo" dos fornecidos por universidades e institutos de pesquisa públicos e privados, agrupando-os sob a denominação

\footnotetext{
3 Mesmo entre as empresas que apostam em um modelo mais fechado de inovação a utilidade dos conhecimentos das universidades é reconhecida, o que costuma envolver laços mais fracos, como os de interações informais, necessárias, por exemplo, à compreensão de documentos de patentes e/ou de artigos científicos.
} 
de "special knowledge providers" (SKP). O elemento central dessa consideração é a crescente importância revelada aos Knowledge Intensive Business Services (KIBS), para os processos de inovação tecnológica e/ou organizacional, por carregarem em si partes essenciais do conjunto de conhecimentos que marcam a complementariedade de muitos processos contemporâneos de inovação ${ }^{4}$.

Trata-se de empresas que fornecem serviços intensivos em informações e conhecimento para outras empresas e que, por isso, são marcadas pela presença de profissionais de alta qualificação, como engenheiros e cientistas, capazes de facilitar o desenvolvimento de soluções a problemas de seus clientes (MILES, 1995; HERTOG, 2000). Os KIBS são fontes externas de informação que facilitam os processos de inovação (HAUKNES, 2005; DOLOREUX e SHERMUR, 2013).

Tether e Tajar (2008) lembram que o fato de os KIBS venderem seus conhecimentos para viver torna maiores suas propensões ao engajamento em atividades cooperativas, em relação às universidades, já que nem sempre o pesquisador universitário se interessa pelos problemas ou pelas demandas industriais. A forte motivação para interação dos KIBS torna crucial a habilidade das firmas industriais em reconhecer quais consultores (KIBS), de fato, estarão comprometidos com esforços para solucionar problemas identificados pela firma. Daí a importância da capacidade de absorção, e do capital social, ou seja, a capacidade de reconhecer e compartilhar de valor implícito dos membros da interação, o que fortalece o aço e ajuda a definir a conformação da rede. A literatura sobre determinantes da inovação já apresenta evidências nesse sentido ${ }^{5}$.

Outro aspecto que será analisado no trabalho e que influencia o engajamento em acordos cooperativos é a origem do capital da empresa. O debate mais interessante a este artigo gira em torno do potencial das subsidiárias de multinacionais em promover maior sofisticação das atividades de inovação levadas a cabo em países em desenvolvimento. De forma geral, a maior parte das atividades de P\&D ainda está fortemente concentrada nas matrizes das grandes corporações transnacionais (GUINET e BAKER, 2008; ALVAREZ et al., 2009). Contribui para isso, a elevada tacitividade e complexidade dos conhecimentos envolvidos no avanço no estado da arte da tecnologia, o que torna

4 Miles (1995) propõe uma subdivisão entre T-KIBS (Technology - Knowledge Intensive Business Services), e P-KIBS (Professional - Knowledge Intensive Business Services). Entre os primeiros, que mais interessam a este trabalho, estão as consultorias em software, design de produto, manutenção de máquina, serviços de telecomunicação, telemática, consultoria em P\&D e em novas tecnologias. Os segundos são os serviços como treinamento, propaganda e marketing, serviços financeiros, jurídicos, de contabilidade, entre outros.

5 Landry et al. (2002), por exemplo, mostram que tanto a decisão de inovar, como o grau de inovatividade a que a empresa se engajará são fortemente relacionados com formas de capital social acumuladas pelas empresas. O trabalho de Zheng (2010) é uma revisão analítica da literatura sobre a relação entre capital social e inovação. 
as interações face a face um fator decisivo ao sucesso de projetos de P\&D e, consequentemente, limitam a descentralização dessas atividades. Adicionalmente, estão os altos níveis de investimento necessários à obtenção de economias de escala, típicas dos grandes projetos, por representarem custos e riscos não desprezíveis. Também o sigilo sobre os resultados representa forças limitadoras da descentralização (ZUCOLOTO, 2009). Nisso reside, basicamente, a explicação para o caráter limitado, menos sofisticado e adaptativo, típico das atividades de P\&D das empresas subsidiárias localizadas em países menos desenvolvidos.

Não obstante, evidências apontam aumento do grau de internacionalização de atividades de $\mathrm{P} \& \mathrm{D}$ não apenas em filiais inseridas em países já desenvolvidos, mas também nos em desenvolvimento. Do ponto de vista da mudança tecnológica global, esse movimento é explicado pelo potencial das novas tecnologias emergentes, notadamente advindas dos conhecimentos científicos em torno da biotecnologia e da nanotecnologia. Isso representa novas oportunidades aos projetos de $\mathrm{P} \& \mathrm{D}$ para diversos países ${ }^{6}$, pois essas tecnologias ainda não foram extensivamente incorporadas aos laboratórios industriais, o que limitaria a difusão. As tecnologias de informação e comunicação também contribuem, por aumentarem o potencial de conectividade dos agentes envolvidos. E ainda, ressaltam-se evidências gerais de que empresas multinacionais procuram diversificar as fontes de informação, criar competências locais e buscar soluções tecnológicas, guiadas pela presença de recursos tecnológicos, tais como centros universitários e institutos de pesquisas em áreas de fronteira tecnológica em diversas partes do mundo (UNCTAD/ITE/IIA, 2006).

De qualquer forma, em quaisquer das concepções, aceita-se que as decisões das subsidiárias estão sempre fortemente limitadas pelas das matrizes. Ainda que, de forma geral, não haja evidências capazes de refutar radicalmente essa compreensão, de acordo com a concepção neo-schumpeteriana da firma, Gomes (2003) aponta que o relativo grau de autonomia tecnológica e gerencial das empresas subsidiárias tende a crescer, à medida que recursos e capacitações estejam sendo acumulados. Nesse sentido, Ariffin e Bell (1999), em estudo sobre subsidiárias do setor de eletroeletrônica da Malásia, mostraram que a capacidade de aprender com a matriz reflete o engajamento em atividades intensivas em tecnologia. Já Marin e Bell (2006) e Marin e Sasidharan (2010), em estudo sobre a Argentina e a Índia respectivamente, mostraram que apenas as subsidiárias voltadas a construção de competências tecnológicas sofisticadas geraram efeitos positivos de spillovers às economias locais. Giroud, Jindra e Marek (2012), reforçam as evidências 6 Reddy (2002), destacou que as novas tecnologias permitem uma sub-divisão das atividades de P\&D em
módulos, aumentando certo nível e forma de descentralização. 
sobre a heterogeneidade do papel do investimento direto externo em economias em desenvolvimento ao apresentarem evidências de que a capacidade tecnológica, o enraizamento local das firmas e a autonomia em relação à matriz mostraram-se positivamente relacionados à transferência de conhecimentos via spillover local em economias do Leste Europeu. Giroud, Ha e Yamin (2014), em análise sobre a economia sul coreana, apontam que as políticas públicas também influenciam as cooperações de P\&D entre matriz e subsidiárias. Esses estudos são exemplos de que os níveis de capacitação interna e a forma como a subsidiária se envolve com fontes globais de conhecimento podem estar diretamente relacionadas à forma como usam os recursos da economia local. Em outras palavras, a conformação de redes locais de conhecimento pode encontrar causa na atitude inovadora da subsidiária.

Para testar essa hipótese, utilizou-se como referência o estudo de Ariffin e Bell (1999) que revelou três formas básicas de aprendizado em que as subsidiárias malaias do setor de eletrônicos se envolveram com as matrizes. A primeira, denominada "interações para o aprendizado para a produção", agrupou firmas cuja interação com a matriz se limitava a construir capacidades operacionais. A cada momento em que a matriz lançava um novo produto, eram realizados ciclos repetitivos de aprendizado pelo treinamento, que apontaram um padrão de aprendizado em que as subsidiárias pareciam confiar nas matrizes para novas tecnologias, mesmo quando upgrades significativos de produtos foram observados. Num segundo grupo, intermediário, notou-se que as interações foram concebidas para intencionalmente fortalecer a capacidade de inovação tecnológica das subsidiárias, por exemplo, através de treinamento de curto prazo em centros de $\mathrm{P} \& \mathrm{D}$ da matriz para desenvolver pequenos projetos. Foram marcantes também as iniciativas independentes das subsidiárias, as quais, em alguns casos se revelaram como o ímpeto fundamental para o desenvolvimento das capacidades inovativas. Além disso, notaram-se maior diversidade e sofisticação das fontes de informação utilizadas nos processos de aprendizagem, o que gerou a saída da situação de "aprender com as matrizes para inovar" para outra de "colaborar para inovar". Um terceiro grupo, de firmas tecnologicamente mais sofisticadas, as subsidiárias adquiriram competência tecnológica em produtos particulares ou atividades nicho, normalmente demonstradas por suas capacidades de completar projetos de mais longo prazo (2 a 5 anos). Nesses casos, a interação resultara em atividades que envolviam atividades colaborativas de $\mathrm{P} \& \mathrm{D}$ e design de novos produtos e processos.

Um último aspecto considerado na análise refere-se ao ambiente de seleção no qual a empresa atua, expresso no seu mercado de atuação. A utilização de fontes externas de conhecimento especializado baseia-se na ideia de que os recursos internos à firma são, em muitos casos, insuficientes para aproveitar economias de escala, reduzir os níveis de incerteza envolvidos no acesso a novos e mais complexos mercados e ex- 
plorar novas oportunidades. A literatura mostra que quanto mais complexo é o mercado de destino da firma, maior é a incerteza relacionada ao sucesso, assim como maior é a exigência em termos de conhecimento requerido (ALVAREZ, 2009).

Essa complexidade pode ser causada por diferenças culturais ou concorrenciais e no caso de empresas de países em desenvolvimento, é requerido um maior esforço para conseguir entrar e se manter em mercados de países desenvolvidos, considerados mais complexos e que requerem, em geral, maior qualidade de produtos. Nesse sentido, também Blalock e Gertler (2004) e Fernandes e Isgut (2015), por exemplo, mostraram que o learning by exporting foi decisivo ao aumento da produtividade de diversos países em desenvolvimento, pois, pela interação com clientes dos países desenvolvidos, tornou possível o compartilhamento de informações e conhecimentos sobre designs e técnicas de produção mais avançados, os quais, teoricamente, estimulam a busca por informações e conhecimentos críticos e, portanto, a formação de redes.

\subsection{AS HIPÓTESES DA PESQUISA}

A investigação empírica deriva de um conjunto de hipóteses que emergem da revisão teórica. A Figura 1 apresenta o sentido do fluxo de informações e conhecimentos considerados:

Figura 1 - Interações entre empresas e unidades provedoras de conhecimento

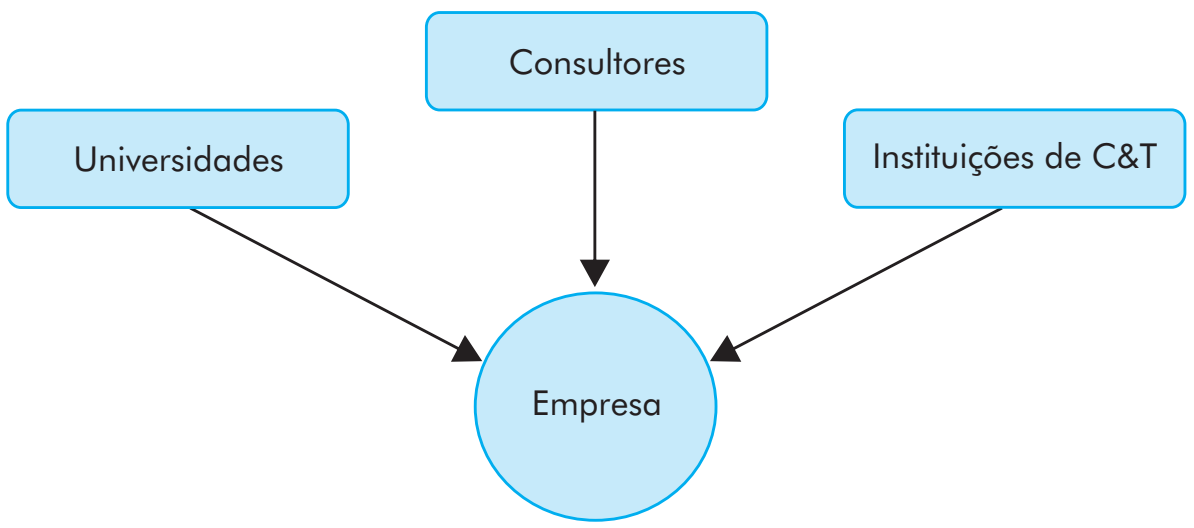

Fonte: Elaboração própria. 
A expectativa é de que o engajamento mais ativo em redes com fornecedores de conhecimentos especializados (FCE) seja verificado segundo:

i) o nível de abertura da empresa (CHESBROUGHT, 2006);

a capacidade de absorção da empresa, captada pela qualificação da mão de obra e pela intensidade das atividades de P\&D (COHEN e LEVINTHAL, 1998; VEGA-JURADO et. al, 2008; INCE, IMAMOGLUA e TURKCANA, 2016);

ii) geração de inovações de maior impacto (radicais) (CALOGHIROU et al., 2004; TÖDTLING et al. 2009; FORÉS e CAMISÓN, 2016);

iii) o tipo de interação que as firmas subsidiárias de multinacionais se envolveram com as matrizes (ARIFFIN e BELL, 1999; MARIN e BELL 2006; MARIN e SASIDHARAN, 2010; GIROUD, JINDRA e MAREK, 2012);

iv) atuação em mercados mais complexos, qualquer que seja a fonte de complexidade (países desenvolvidos, culturas diferentes etc.), como uma forma de diminuir a incerteza relacionada a qualquer aspecto desta maior complexidade (ALVAREZ, 2009; FERNANDES e INSGUT, 2015).

\section{FONTE DE DADOS E ESTRATÉGIA METODOLÓGICA}

A fonte de microdados deste trabalho é o survey "Encuesta Nacional de Dinámica de Empleo e Innovación" (ENDEI), desenvolvida pelo Ministerio de Trabajo, Empleo y Seguridad Social (MTEySS) em parceria com o Ministerio de Ciencia, Tecnología e Innovación Productiva da Argentina e com o Banco Interamericano de Desenvolvimento (BID). A pesquisa foi elaborada no período de setembro de 2013 a julho de 2014 referente ao período de 2010 a 2012 no marco do Programa de Inovação Tecnológica II do BID.

A ENDEI integra uma análise dos perfis e modelos inovativos das empresas do setor manufatureiro argentino contemplando a relação funcional entre emprego, relações institucionais e inovação, de forma a mensurar os impactos do processo inovador sobre diferentes variáveis associadas ao desempenho das empresas. Os temas cobertos pela ENDEI são: estrutura empresarial, capacidade organizativa e estratégia empresarial.

A pesquisa foi realizada a partir de amostragem por setor de atividade e tamanho, entre empresas industriais de todo o país, com 10 ou mais pessoas ocupadas. As empresas precisavam, também, serem registradas no SIPA (Sistema Integrado Provisional Argentino), sistema que acumulava, em 2011, dados de 18.900 empresas industriais com 10 ou mais empregados ocupados. Cada cruzamento entre o setor ${ }^{7}$ e tamanho se transforma em um estrato representativo.

\footnotetext{
7 Os setores de atividade foram agrupados de forma que os estratos resultantes tivessem tamanho populacional superior a 70 casos, de forma a poder extrair amostras não inferiores a 40 casos, o que permitiria
} 
Para selecionar a amostra, é aplicado um algoritmo de seleção sistemática com probabilidade igual em todos os estratos, menos nos considerados autorrepresentados (com menos de 70 empresas no setor). O resultado é uma amostra integrada por 3.995 empresas industriais de 10 ou mais trabalhadores. Há necessidade de considerar as ponderações utilizadas no momento de realizar as estimações, utilizando, para isto, o fator de expansão fornecido pela ENDEI.

Para concentrar as variáveis relacionadas, como tamanho da rede externa de conhecimento das empresas argentinas, construiu-se uma variável [Rede] que atribui às empresas valores discretos de zero a três, em ordem crescente com os vínculos. Esses vínculos podem ocorrer com Universidades públicas ou privadas, com Instituições Públicas de Ciência e Tecnologia ${ }^{8}$ e com Consultores. As finalidades desses vínculos são: capacitação de recursos humanos, pesquisa e desenvolvimento, transferência tecnológica, atividades de desenho industrial e/ou provas, ensaios e testes.

$\mathrm{O}$ valor atribuído à formação de vínculos entre a empresa e os três agentes FCE depende apenas do número de vínculos que a empresa estabeleceu, não dependendo da instituição e da finalidade. Assim, recebem valor 0 as empresas que não possuem vínculos com outras instituições; recebem valor 1 as empresas que se vinculam com apenas um tipo de instituição; 2 as que se vinculam com duas instituições diferentes; e 3 as que se relacionam com os três tipos de instituições. Como a variável dependente aparece como uma variável ordinal, utiliza-se, nesta análise, um modelo probit ordenado?.

No probit ordenado existe uma variável latente $(Y)$ que associa números aos resultados da seguinte forma: $Y_{i}=j$, se $\theta_{j-1}<Y_{i}<\theta_{j}$, em que $j$ assume valores discretos de zero a três e os valores limites (threshold), $\theta_{j}$, são partições da distribuição normal padrão em quatro intervalos, desconhecidos e determinados endogenamente pelo modelo. Logo, a partir da função

$$
Y_{i}=\alpha+\beta^{\prime} X_{i}+\varepsilon_{i}
$$

em que $\alpha$ é uma constante, $\beta$ um vetor de parâmetros, $X_{i}$ uma matriz de variáveis exógenas e $\varepsilon_{i}$ um componente aleatório com distribuição $N(0,1)$, chega-se, a partir das carac-

obter coeficientes de variação aceitáveis.

8 Entre estas o Ministério de Ciência, Tecnologia e Inovação Produtiva (MINCyT) e a Agencia Nacional de Promoção Científica e Tecnológica (La Agencia), Conselho Nacional de Investigações Científicas e Técnicas (CONICET), Comissão Nacional de Energia Atómica (CNEA), Instituto Nacional de Tecnologia Agropecuaria (INTA), Instituto Nacional de Tecnologia Industrial (INTI), Instituto Nacional da Propriedade Industrial (INPI), entre outras.

9 Para uma explicação mais detalhada deste modelo, ver Greene (2010). 
terísticas da empresa " $i$ ", a um valor para $Y_{i}$ que identificará qual o número de vínculos com instituições diferentes que essa empresa tem maior probabilidade de ter. No entanto, o foco da análise é a significância e o sinal dos parâmetros $\beta$, que vão dizer quais variáveis têm relação com o tamanho da rede das empresas e se essa relação é positiva ou negativa.

Quanto às variáveis independentes, parte delas foi extraída diretamente da base de dados (ENDEI) e outras variáveis foram construídas a partir dessa mesma base. As variáveis utilizadas foram selecionadas com base na teoria ${ }^{10}$. Para melhor estimação do modelo, utilizam-se como controle as variáveis setor de atividade ${ }^{11}$ [S_A(n ${ }^{\circ}$ do setor)], empresa familiar [Empresa_familiar], ambas binárias, e a variável tamanho da empresa [Tamanho_empresa], identificada pelos valores 1, 2 e 3, respeitando a medida pequena, média ou grande, respectivamente. A seguir, apresentam-se as variáveis e os fundamentos conceituais/analíticos que se pretende investigar a partir delas:

- P\&D como atividade contínua [PeD_continua]: dummie que caracteriza o comprometimento com P\&D pela firma. Um indicador de sua capacidade absortiva, mas também indica o engajamento na atividade de inovação complexas, marcadas por alta incerteza do resultado e potencial de impacto ( $\mathrm{H} 1$ e H3).

- Fontes de informação [Fontes_informação]: recebe valores discretos de 0 a 7 , que se relacionam à quantidade de fontes de informação externas utilizadas pela empresa, com: outras empresas do grupo, fornecedores ou clientes, competidores, internet e redes de informação, câmaras empresariais, feiras e congressos e publicações técnicas e catálogos ou revistas do setor. Quanto maior o número de fontes de informação utilizadas, mais aberta a empresa e maior sua capacidade absorção (H1 e H2).

- Fontes de informação ao quadrado [Fontes_informação2]: é simplesmente o valor da variável Fontes_informação elevado ao quadrado. Novamente, o modelo de inovação (aberta ou fechada) e a capacidade de absorção são os princípios. Pressupõe-se, no entanto, um efeito exponencial do uso de fontes de informação sobre a formação de redes (H1 e H2).

- Proporção de profissionais especializados [Prop_(profissionais)]: proporção média (entre 2010 a 2012) de profissionais engenheiros e das áreas de ciências naturais e exatas dentro do quadro total de empregados [engenheiros]; e da proporção de profissionais de desenho industrial e das áreas de ciências sociais

${ }^{10}$ Veja-se a seção de revisão teórica e bibliográfica.

11 A base contém 27 setores de atividades diferentes, identificados por dummies no modelo e especificados na Tabela A.1 dos Anexos. O setor de alimentos foi utilizado como referência para estimação. 
e administrativas, ciências médicas e outros, dentro do quadro total de empregados [outros]. Novamente a capacidade de absorção é investigada. Essa dimensão também permite inferir sobre o capital social, se o número de graduados estiver relacionado à formação de vínculos com outras instituições que também costumam absorver esses tipos de graduados, como as FCE (H2).

- Gastos com inovação [Ln_gasto_inovação]: representa a média dos anos 2010 a 2012 do logaritmo dos gastos com atividades de inovação. A variável procura captar esforços em inovação além dos de P\&D, tais como: treinamento, com a implementação dos produtos, com atividades internas de engenharia, e com a aquisição externa de tecnologia. Admite-se que quanto maior esse esforço, maior a capacidade de absorção das firmas (H2).

- Inovação radical [Inovação_radical]: dummie que indica se a empresa implementou uma inovação radical durante o período da entrevista. Assume-se que houve inovação radical se a empresa desenvolveu novos produtos, processos ou inovações organizacionais para o mercado nacional ou internacional. A expectativa é de que o significativo conjunto de conhecimentos necessários para a introdução de inovações de maior impacto estimule a formação de redes com fornecedores especializados (H3).

- Pertence a um grupo de empresas [Grupo_empresarial]: dummie que mede o efeito de uma empresa pertencer a um grupo empresarial. Empresas nessa situação podem, por um lado, utilizar conhecimento do grupo e dispensarem auxílio especializado externo. Por outro lado, a experiência na interação de aprendizado pode estimular a busca de conhecimentos junto a um FCE, o que pode ampliar os resultados do investimento realizado. Por isso, espera-se que o efeito desta variável seja favorável à criação de vínculos com FCE (H4).

- Participação do capital internacional [Cap_internacional]: dummie que identifica se a empresa da amostra possui participação do capital internacional. Admite-se que esta variável esteja associada à presença de empresas subsidiárias de multinacionais, as quais tenderiam a se associar com FCE para adaptação de seus produtos e processos à demanda e condições locais (H4).

- Participação do capital internacional com vínculos a sua matriz e/ou outras empresas do grupo. Restringe a amostra para analisar o caso mais específico das empresas subsidiárias que se vinculam à sua matriz e/ou outras empresas do grupo para capacitação de recursos humanos, gestão de qualidade ou intercâmbio organizacional [Aprend_produção]; desenvolvimento ou melhora de produtos e processos, transferência tecnológica ou provas, ensaios e testes de equipamentos e produtos [Aprend_inovação]; pesquisa e desenvolvimento ou atividades de desenho industrial [Coop_inovação]. Todas dummies (H4).

- Empresa exportadora: Dummie que recebe valor um caso a empresa possua um cliente de fora do país [Empresa_exportadora] e, de forma mais específica, analisa a relevância do mercado do cliente [Clientes_(mercado)], sendo eles Mer- 
cosul [Mercosul], Outros da América Latina[AL], Estados Unidos e Canadá [EUACan], Europa [Euro], Ásia [Asia] e África e Oceania [AfricaOce]. Com essas variáveis pretende-se captar a influência da atuação em mercados complexos para o engajamento das firmas em FCEs (H5).

As estatísticas descritivas são apresentadas na Tabela 1. A análise aponta um restrito volume de redes com FCE entre as empresas inovadoras argentinas. Em média, cada firma teria se envolvido com “0,63 FCEs”. Também a busca de conhecimento externo não é impressionante, com a média de 2,04 fontes externas por firma. O quadro profissional é formado por $2 \%$ de engenheiros e $4 \%$ de especialistas de outras áreas especializadas. Além disso, gastam com inovação, em média, cerca de US\$ 750 por ano e apenas $7 \%$ implementaram inovações para o mercado nacional ou mundial [radicais].

Tabela 1 - Estatísticas descritivas das variáveis utilizadas

\begin{tabular}{|c|c|c|c|c|c|}
\hline Variável & $\mathbf{N}^{\circ}$ observações & Média & Desvio Padrão & Mínimo & Máximo \\
\hline Rede & 3691 & 0,63 & 0,910 & 0 & 3 \\
\hline Fontes_informação & 3691 & 2,04 & 2,156 & 0 & 7 \\
\hline Cap_internacional & 3691 & 0,09 & 0,288 & 0 & 1 \\
\hline Empresa_exportadora & 3691 & 0,39 & 0,487 & 0 & 1 \\
\hline Prop_engenheiros & 3691 & 0,02 & 0,048 & 0 & 0,52 \\
\hline Prop_outros & 3691 & 0,04 & 0,095 & 0 & 1 \\
\hline Ln_gasto_inovação & 3691 & 8,03 & 6,231 & 0 & 19 \\
\hline Tamanho_empresa & 3691 & 1,78 & 0,766 & 1 & 3 \\
\hline PeD_contínua & 3691 & 0,40 & 0,491 & 0 & 1 \\
\hline Grupo_empresarial & 3691 & 0,12 & 0,329 & 0 & 1 \\
\hline Empresa_familiar & 3691 & 0,70 & 0,457 & 0 & 1 \\
\hline Inovação_radical & 3691 & 0,07 & 0,249 & 0 & 1 \\
\hline Fontes_informação2 & 3691 & 8,80 & 12,291 & 0 & 49 \\
\hline Aprend_produção & 3691 & 0,005 & 0,070 & 0 & 1 \\
\hline Aprend_inovação & 3691 & 0,01 & 0,087 & 0 & 1 \\
\hline Coop_inovação & 3691 & 0,04 & 0,190 & 0 & 1 \\
\hline Clientes_Mercosul & 3691 & 0,34 & 0,473 & 0 & 1 \\
\hline Clientes_AL & 3691 & 0,24 & 0,424 & 0 & 1 \\
\hline Clientes_EUACan & 3691 & 0,09 & 0,281 & 0 & 1 \\
\hline Clientes_Euro & 3691 & 0,11 & 0,307 & 0 & 1 \\
\hline Clientes_Ásia & 3691 & 0,08 & 0,275 & 0 & 1 \\
\hline Clientes_ÁfricaOce & 3691 & 0,05 & 0,227 & 0 & 1 \\
\hline
\end{tabular}


Fonte: Elaboração própria com base nos dados da Endei (2014).

A maioria das empresas é de pequeno e médio porte e não realiza $\mathrm{P} \& \mathrm{D}$. Apenas 9\%, contam com capital internacional, e menos de 0,5\% mantiveram interações com outras empresas do grupo ou com sua matriz, para o desenvolvimento de inovações. Trata-se de 70\% de empresas familiares. Pouco mais de um terço exportam para o Mercosul, pouco mais de um quarto, para a América Latina e cerca de 10\% exportam para outros mercados.

A descrição dos setores de atividade das empresas argentinas encontra-se na Tabela A.1 dos Anexos, que aponta a representatividade de setores tradicionais na economia argentina. O maior setor é o de alimentos, abrangendo 9,1\% do total da amostra, seguido por outros tradicionais, como o de produtos de metal e têxteis. De fato, o parque industrial argentino é marcado pela grande presença de setores de baixa intensidade tecnológica, reunindo cerca de $48 \%$ do total das empresas, seguido pelos setores de médio-baixa e médio-alta tecnologia, com cerca de $20 \%$ em cada grupo, e os setores alta intensidade tecnológica, menos de $10 \%$ do total.

\section{ESTRUTURA TECNOPRODUTIVA E POLÍTICAS DE CT\&I NA ARGENTINA.}

Esta seção expõe, de forma resumida, aspectos do Sistema Nacional de Inovações Argentino, com foco em características de sua estrutura produtiva e nas políticas públicas de C\&T que procuram, sobretudo desde 2003, aumentar os estímulos a geração de inovações no SNI.

Uma das principais características do SNI argentino reside na dependência tecnológica marcada por processos de inovação intensamente direcionados à aquisição de máquinas e equipamentos do exterior. Nesse sentido, assim como no SNI brasileiro, um dos principais desafios é construir competências tecnológicas inovadoras nas empresas, as quais costumam estar apoiadas em instituições do entorno.

O tecido produtivo argentino é marcado por destacado papel da cadeia agroalimentar em uma estrutura industrial relativamente diversificada e por um conjunto de novos setores de base tecnológica, os quais, mesmo não se destacando na escala mundial, apresentam um comportamento diferenciado no cenário nacional.

Para que se possa ter uma noção do peso da cadeia agro-alimentar vale destacar alguns números. A produção agropecuária chega a responder por cerca de $5 \%$ do PIB. O setor industrial relacionado, de alimentos e bebidas, representa aproximadamente $25 \%$ do valor da transformação industrial, o qual está, sobretudo, direcionado ao processamento de carnes e de laticínios. Também se vê nas exportações os reflexos dessa especialização. Mais da metade da pauta é formada por produtos primários agro-ali- 
mentares. Moldovan et al. (2011) destacaram que o setor passou recentemente por um processo de profunda transformação marcado pela adoção de novas tecnologias, incluindo vinculadas a manipulação genética no campo. Adicionalmente, afirmaram que o dinamismo tecnológico da cadeia é dominado por empresas multinacionais.

No que se refere ao setor industrial, é significativa a presença de fornecedores especializados das indústrias metalmecânica, siderúrgica e química, além de intensivos em mão de obra como têxtil e de confecções e outros dominados por multinacionais, como o automobilístico. A reestruturação produtiva em âmbito internacional do setor automobilístico imprimiu grandes dificuldades aos fornecedores locais, destruindo grande parte das competências criadas pelas políticas públicas de outrora.

Moldovan et al. (2011) chamam atenção para a indústria farmacêutica argentina, por ter emergido de um conjunto de políticas de incentivo à produção nacional e que resultaram em interessantes capacidades inovadoras. As políticas incluíram o não reconhecimento de patentes internacionais, um grau elevado de proteção, além de uma política de preços baixos para a aquisição de insumos, desde a década de 1960. Com o marco regulatório modificado em prol da estratégia neoliberal da década de 1990, muitos laboratórios quebraram. Não obstante, recentemente, com a sanção da Lei dos Genéricos e com a melhora das condições econômicas dos últimos anos, muitos laboratórios estrangeiros deixaram de produzir na Argentina, passando a realizar alianças com os Laboratórios Nacionais. Como resultado, atualmente, cerca de 55\% da produção é realizada por empresas de capital argentino.

Finalmente, entre os setores surgidos do paradigma das TICs, destaca-se o setor de software, que tem revelado bom desempenho, sustentado por mão de obra qualificada, assim como por programas de incentivo local.

No que se refere a estrutura de apoio institucional, é decisivo marcar a crise de 2001/2002 como ponto de inflexão na estratégia de dotar o SNI de melhores condições para inovar. De fato, após a profunda crise social, política e econômica que a Argentina atravessou, nos anos de 2001-2002, a recuperação, a partir de 2003 se caracteriza, no âmbito do SNI, por aumentos sustentados do orçamento para o sistema de ciência, tecnologia (C\&T) e educação superior. O investimento em C\&T, que alcançou o seu piso histórico em 2002 (0,39\% do PIB), chega a 0,61\% do PIB em 2012-2014 (segundo dados do Banco Mundial), a partir do investimento público, privado e internacional.

No processo de recuperação institucional e fortalecimento do SNI, não pode deixar de destacar-se, segundo Gordon (2016) o caso do Conselho Nacional de Investigações Científicas e Tecnológicas (CONICET), que começou uma nova gestão em 2002 que ampliaria e fortaleceria o principal organismo executor de $\mathrm{P} \& \mathrm{D}$ da Argentina.

Na Figura 1, se apresenta esquematicamente os principais atores do Sistema de Ciência, Tecnologia e Inovação da Argentina, concentrado fortemente em órgãos na- 
cionais de formulação de políticas, direção e coordenação, especialmente o Ministério de Ciência, Tecnologia e Inovação Produtiva (MINCyT), o Conselho Federal de Ciência e Tecnologia (COFECyT) e a Agencia Nacional de Promoção Científica e Tecnológica (ANPCyT). O Conselho Interministerial de Ciência e Tecnologia (CICyT) é a instituição encarregada de coordenar os ministérios com os órgãos públicos executores de $\mathrm{P} \& \mathrm{D}$.

Figura 1- Sistema de Ciência, Tecnologia e Inovação da Argentina

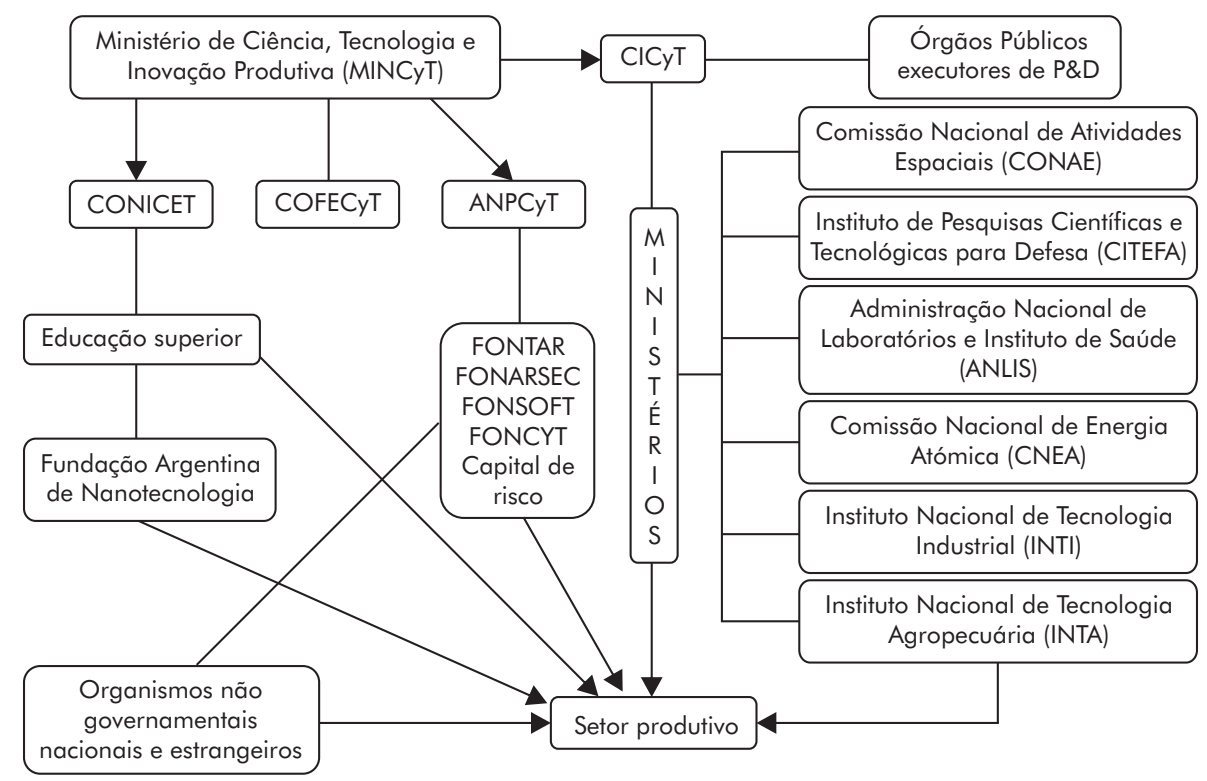

Fonte: Resumido e adaptado de Gordon (2011).

A partir de 2003, se incorporam mais de 1 mil bolsistas de doutorado e pós-doutorado por ano, além ser restabelecido o ingresso à carreira de pesquisador científico que tinha sido congelado desde a década de 1990. Em 2002, o número de pesquisadores do CONICET era de 3,8 mil, passando, em 2013, a 9 mil $^{12}$. Boa parte destes recursos humanos está nas áreas de ciências exatas e naturais (30\%), médicas (14\%), engenharias e tecnologias (18\%), onde o país possui uma grande tradição. Porém, uma debilidade deste esforço se encontra no fato de que só $10 \%$ destes pesquisadores desempenham seu trabalho em empresas privadas. O CONICET conta com 105 institu-

12 Dados de Conicet: <http://www.conicet.gov.ar/conicet-30-anos-de-democracia/>. 
tos de pesquisa, 32 Laboratórios Nacionais de Pesquisa e Serviços e seis centros regionais, que articulam a relação com as universidades e províncias.

A recuperação institucional posterior a 2003 chegou também a organismos descentralizados de execução de políticas de $\mathrm{P} \& \mathrm{D}$, tais como o Instituto de Tecnologia Agropecuária (INTA), a Comissão Nacional de Energia Atómica (CNEA), a Comissão Nacional de Atividades Espaciais (CONAE), que ganharam autonomia e maior orçamento para as suas atividades.

O Plano Estratégico do Bicentenário, implementado pelo MINCyT a partir de 2008, tinha como um dos seus objetivos principais alcançar 1\% do PIB em investimento em C\&T, objetivo que não foi alcançado, consequência não só da dificuldade de aumentar o gasto público, mas especialmente da complexidade para alavancar o investimento privado. Moldovan et al. (2011) atribuem esta dificuldade ao perfil produtivo argentino, caracterizado por setores com baixo dinamismo tecnológico ou que concentram o esforço inovador nas matrizes.

Vale dizer ainda, no que se refere ao financiamento internacional, que a Argentina tem sido o país da América Latina que mais apoio recebeu na forma de empréstimos para C\&T (Aguiar et al., 2015), desde a implementação, dos diferentes estágios do Programa de Modernização Tecnológica (PMT) em 1993.

Nota-se, portanto, que o SNI argentino é marcado pela forte presença da atividade produtiva tradicional, partes da cadeia agroalimentar, mas com grandes possibilidades de desenvolvimento tecnológico recente estimulado pelas novas soluções em campos como a biotecnologia. Além disso, conta com uma estrutura produtiva relativamente diversificada, mas tecnologicamente dependente e marcada pela forte presença de multinacionais. Há, apesar disso, segmentos promissores como o de software e de farmacêutica. Essa estrutura produtiva tem sido apoiada direta e indiretamente por políticas de incentivo tecnológico, especialmente desde 2003, as quais podem ser a semente de uma superação de debilidades históricas do SNI.

\section{RESULTADOS}

Na Tabela A.1 dos Anexos, nota-se que os vínculos estão concentrados em setores tradicionais, tais como alimentos, têxteis, confecções e madeira. Isso está refletido também na Figura 2 abaixo, que revela grande parte dos vínculos concentrados nos setores de baixa intensidade tecnológica (BT), seguido pelos de médio-alta tecnologia (MAT), médio-baixa (MBT) e de alta tecnologia (AT).

Os resultados mudam, no entanto, quando o foco se centra nas proporções de empresas que se engajaram em vínculos com FCE. A formação de redes com FCE é mais frequente em setores mais intensivos em tecnologia, algo esperado, conside- 
rando-se a diversidade de conhecimentos tipicamente necessários aos processos de inovação. No setor de alta intensidade tecnológica, pouco mais de $50 \%$ das empresas engajaram-se com pelo menos um FCE, $20 \%$ com dois e $12 \%$ com os três. Nos demais segmentos, as proporções caem em relação direta com o nível de intensidade tecnológica. A proporção de empresas que se engajaram em redes com dois FCE, por exemplo, foi de $8 \%$ no setor de média alta tecnologia (MAT), de 5\% nos de média baixa tecnologia (MBT) e apenas 3\% entre os de baixa intensidade tecnológica (BT).

Atenção adicional merece o fato do uso dos consultores serem mais proeminente entre os FCE considerados, o que também já era esperado, dado que "eles vendem seus conhecimentos para viver" (TETHER e TAJAR, 2008). Nota-se, no entanto, que em relação aos demais FCE (universidades e centros de C\&T), quanto maior a intensidade tecnológica menor a importância relativa dos consultores, certamente por, no geral, disponibilizarem conhecimentos menos sofisticados. Isso sustenta a importância das universidades e centros tecnológicos como provedores de conhecimentos mais complexos e de fronteira, necessários a processos de inovação mais sofisticados, típicos de setores intensivos em conhecimento e tecnologia.

Figura 2 - Números de vínculos criados pelas empresas da amostra de acordo com o nível médio de intensidade tecnológica do setor: Baixa Tecnologia (BT), MédiaBaixa Tecnologia (MBT), Média-Alta Tecnologia (MAT) e Alta Tecnologia (AT)

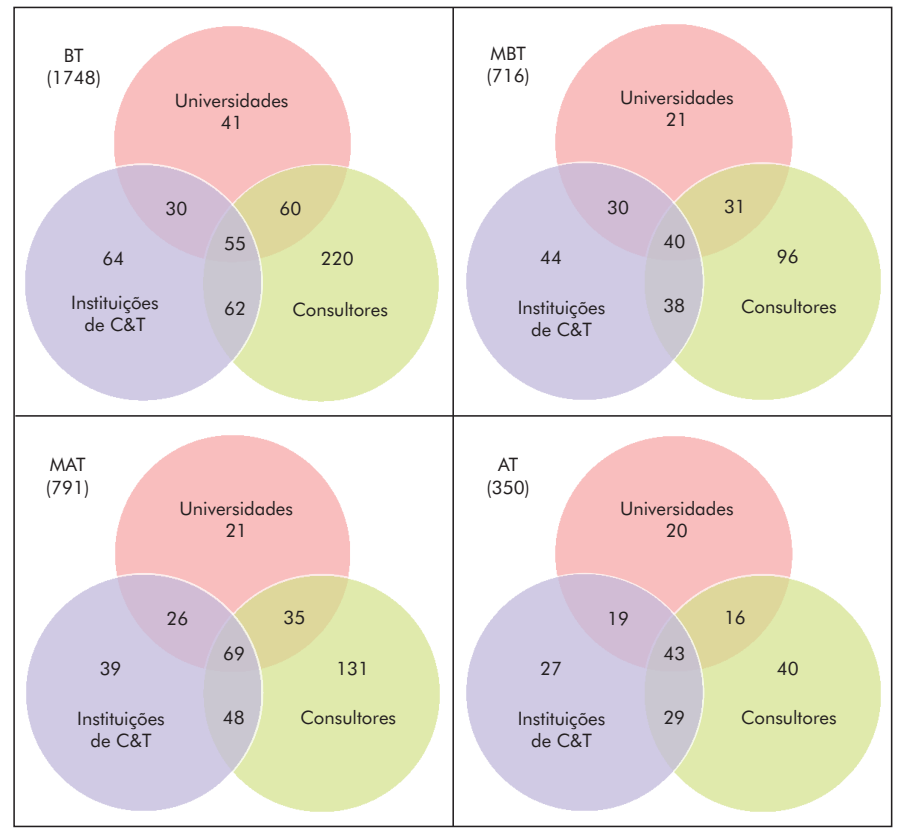

Nota: número total de empresas entre parênteses.

Fonte: Elaboração própria com base nos dados da Endei (2014). 
Após a análise geral dos vínculos criados pelas empresas com provedores de conhecimento especializado, cabe verificar a relação entre características das empresas investigadas e a probabilidade de aumentar o número de vínculos estabelecidos com FCE. Para isso, quatro modelos foram estimados através da abordagem probit ordenado, cujos resultados são apresentados na Tabela 2. Destaca-se que a variável dependente é o número de vínculos que a empresa estabelece com FCE.

Tabela 2 - Probit ordenado: resultados da regressão para o tamanho da rede - todos os modelos

\begin{tabular}{|c|c|c|c|c|}
\hline Variável $^{1}$ & Modelo 1 & Modelo 2 & Modelo 3 & Modelo 4 \\
\hline Fontes_informação & $0,120^{*+*}$ & n.c. & $0,119^{* * *}$ & $0,119^{* * * *}$ \\
\hline Cap_internacional & 0,059 & 0,060 & n.c. & n.c. \\
\hline Empresa_exportadora & $0,255^{* * *}$ & $0,257^{* * *}$ & $0,254^{* * *}$ & n.c. \\
\hline Prop_engenheiros & $1,644^{* * *}$ & $1,671^{* * *+}$ & $1,682^{n+* x}$ & $1,620^{* * *}$ \\
\hline Prop_outros & $0,526^{*}$ & $0,511^{* *}$ & $0,477^{*}$ & $0,460^{*}$ \\
\hline Ln_gasto_inovação & $0,024^{* * *}$ & $0,034^{* * * *}$ & $0,024^{* * * x}$ & $0,024^{* * *}$ \\
\hline Tamanho_empresa & $0,237^{+* * *}$ & $0,225^{* * *}$ & $0,229^{* * * *}$ & $0,221^{* * *}$ \\
\hline P\&D_contínua & $0,276^{* * *}$ & $0,293^{* * *}$ & $0,280^{+* * *}$ & $0,276^{* * *}$ \\
\hline Grupo_empresarial & 0,122 & 0,096 & 0,034 & 0,024 \\
\hline Empresa_familiar & 0,025 & 0,028 & 0,041 & 0,044 \\
\hline Inovação_radical & $0,412^{*+*}$ & $0,413^{* * *}$ & $0,400^{n+x}$ & $0,413^{* * *}$ \\
\hline Fontes_informação2 & n.c. & $0,018^{* * *}$ & n.c. & n.c. \\
\hline Coop_inovação & n.c. & n.c. & $0,449^{n+x}$ & $0,426^{* * *}$ \\
\hline Aprend_inovação & n.c. & n.c. & $0,461^{* *}$ & $0,427^{* *}$ \\
\hline Aprend_produção & n.c. & n.c. & 0,029 & 0,043 \\
\hline Clientes_Mercosul & n.c. & n.c. & n.c. & $0,192^{* * *}$ \\
\hline Clientes_AL & n.c. & n.c. & n.c. & $0,165^{* *}$ \\
\hline Clientes_EUACan & n.c. & n.c. & n.c. & $-0,307^{* * *}$ \\
\hline Clientes_Euro & n.c. & n.c. & n.c. & 0,006 \\
\hline Clientes_Asia & n.c. & n.c. & n.c. & $0,285^{* *}$ \\
\hline Clientes_AfricaOce & n.c. & n.c. & n.c. & 0,006 \\
\hline Corte 1 & 1,434 & 1,408 & 1,428 & 1,406 \\
\hline Corte 2 & 2,324 & 2,298 & 2,320 & 2,302 \\
\hline Corte 3 & 3,162 & 3,138 & 3,162 & 3,153 \\
\hline Valor Pseudo R2 & 0,1556 & 0,1552 & 0,1569 & 0,1596 \\
\hline Wald Chi2 & 748,03 & 768,16 & 778,78 & 798,77 \\
\hline AIC & 29509,23 & 29525,48 & 29468,03 & 29386,54 \\
\hline
\end{tabular}

\footnotetext{
1 Além dessas variáveis, os setores de atividade foram utilizados como controles.
}

Nota: Número de observações - 3691. ***Significante a 1\%; **Significante a 5\%; e, *Significante a $10 \%$.

Fonte: Elaboração própria com base nos dados da Endei (2014). 
O Modelo 1 serve como base de comparação para os modelos subsequentes, os quais alteram as variáveis utilizadas de modo a aprofundar a investigação sobre a relação entre características das empresas e o tamanho da rede de conhecimento especializado (FCE) com a qual se envolve. As variáveis do Modelo 1 são: (i) número de fontes externas de informação; (ii) participação do capital internacional; (iii) se exporta; (iv) proporção de engenheiros no total de empregados; (v) proporção de outros profissionais especializados; (vi) logaritmo dos gastos com inovação; (vii) tamanho da empresa; (viii) se faz P\&D contínuo; (ix) se faz parte de um grupo empresarial; (x) se a empresa é familiar; e (xi) se implementou inovação radical (para o mercado nacional/mundial).

No Modelo 1, o número de vínculos criados com FCE esteve relacionado de forma positiva com variáveis que inferem sobre quase todas as hipóteses. Correlações positivas revelaram-se nas medidas de abertura da empresa $(\mathrm{H} 1)$ - número de fontes de externas de informação; de capacidade de absorção (H2) - tanto as de nível de mão de obra dos recursos humanos especializados, como a presença de setor de P\&D contínuo e o esforço global de inovação; de geração de inovações de maior impacto (H3) inovação radical; e da presença em mercados externos via atividade de exportação (H5). Nesse modelo, no entanto, H4 não pode ser aceita, pois nem a participação de capital internacional, proxy de subsidiária, nem o fato de a empresa pertencer a um grupo empresarial revelaram-se significativas. Entre as variáveis de controle, cabe destacar a correlação significativa do porte empresarial, apontando os recursos acumulados pelas empresas, via maior escala, como fator significativo ao estabelecimento de vínculos com redes sofisticadas de inovação.

O Modelo 2 não confirma para a Argentina o resultado encontrado por Tether e Tajar (2008) para o Reino Unido, ou seja, o efeito exponencial do uso de um número crescente de fontes externas de informação sobre a propensão das firmas em se engajar em redes com fornecedores especializados. Neste modelo, que substituiu a variável "fontes de informação" por "fontes de informação ao quadrado", o resultado do grau de ajuste (Pseudo $\mathrm{R}^{2}$ e AIC) foi menor que no Modelo 1 , indicando que essa variável é mais bem utilizada quando seus valores são considerados de forma linear.

O Modelo 3 permite aceitar a hipótese 4, depois de algumas considerações sobre o grau de relacionamento com outras empresas do grupo ou sua matriz. Como vimos, pelo Modelo 1, não se confirmou a expectativa de que a participação de capital internacional nas empresas locais pudesse trazer informações e exigências que necessitassem de conhecimento dos FCE. Contudo, o uso de variáveis definidas a partir do estudo de Ariffin e Bell (1999), com a intenção de captar diferentes atitudes inovadoras das subsidiárias a partir das formas de interação com a matriz, revelou impacto positivo da atitude inovadora da subsidiária na formação de redes com fornecedores de conhecimentos especializados. 
O resultado obtido no Modelo 3 revelou que empresas que se relacionam com a matriz via atividades de $\mathrm{P} \& \mathrm{D}$ ou de desenho industrial, assim como para desenvolvimento ou melhorias de processos, transferência tecnológica, provas e ensaios têm maior probabilidade de fazer uso mais intensivo da estrutura local de conhecimentos especializados (universidades, instituições de C\&T e consultores), do que as que não mantêm igual nível de relacionamento ou aquelas que se relacionam apenas para capacitação de recursos humanos, gestão de qualidade ou trocas organizacionais. Claramente, a forma com que a subsidiária interage com a matriz importa para que a estrutura local de conhecimento seja objeto da formação de redes. Isso sugere que o envolvimento em processos de aprendizado mais intensivos em conhecimento pelas subsidiárias, ajudem a explicar o enraizamento de interações virtuoso com instituições locais.

O resultado do Modelo 3 destaca outro aspecto abordado na revisão teórica: firmas de capital internacional operam de acordo a múltiplos objetivos (MARIN e SASIDHARAN, 2010; GIROUD, JINDRA e MAREK, 2012), mas havendo organização integrada, as estratégias e decisões permitem a exploração de ativos tecnológicos que, para serem aproveitados, requerem a interação com um maior número de entidades especializadas em conhecimento. Em vista disto, as redes tendem a se formar mesmo em países em desenvolvimento tecnologicamente retardatários como a Argentina.

O Modelo 4, o melhor modelo estimado de acordo com os testes Pseudo $\mathrm{R}^{2}$ e AIC, avança ao levar em conta o continente (ou bloco econômico, no caso do Mercosul) para os quais as empresas argentinas exportam, o que é uma proxy para mensurar o ambiente de seleção ao qual as empresas estão expostas em dois sentidos: em primeiro lugar, porque a base de comparação é o mercado doméstico, logo, exportar configura acessar a mercados mais complexos. Em segundo lugar, as categorias incorporam diferentes mercados de exportação: exportar ao Mercosul requer habilidades diferentes de exportar para mercados de países desenvolvidos, cujas demandas são mais sofisticadas, como Europa ou Estados Unidos.

O Modelo 4 revela que exportar para mercados do Mercosul, América Latina e Ásia está positivamente relacionado com maiores vínculos formados por essas empresas com FCE, diferente do que ocorre com empresas que exportam para o mercado norte-americano e canadense, cuja relação é negativa, ou seja, empresas que exportam para essa região tendem a fazer poucos ou nenhum tipo de vínculo com essas instituições consideradas. Desta forma, os resultados corroboram só parcialmente a nossa hipótese e a teoria que trata desta relação.

A Tabela 3 sugere que a explicação para esse contraste reside na proporção de empresas exportadoras de segmentos mais intensivos em tecnologia para as regiões cujo coeficiente foi positivo e significativo. Com base na tabela, constata-se que aproximadamente 1/3 das empresas exportadoras para a América Latina e Mercosul pertence a setores de 
baixa intensidade tecnológica. Essa proporção é superior a 50\% no caso entre as exportadoras para EUA/Canadá, mas também para a Ásia. Entre esses últimos destinos, no entanto, é marcante a diferença do percentual de empresas exportadoras de setores de alta intensidade tecnológica. Para a Ásia, elas chegam a ser aproximadamente $17 \%$ do total, com forte participação do setor farmacêutico, o qual, como vimos acima foi construído por década de esforços de política pública agentina. Enquanto que, para os EUA/ Canadá, os setores de AT exportam apenas pouco mais de $8 \%$ do total.

\section{Tabela 3 - Empresas com clientes internacionais por nível médio de intensidade tecnológica do setor em que atua e sua representatividade nas exportações por região}

\begin{tabular}{lcccccccccc}
\hline & & \multicolumn{8}{c}{ N $^{\circ}$ empresas por nível tecnológico do setor } & \\
Clientes no(a): & BT & $\%$ & MBT & $\%$ & MAT & $\%$ & AT & $\%$ & Total & $\%$ \\
\hline Mercosul & 409 & 34,00 & 242 & 20,12 & 387 & 32,17 & 165 & 13,72 & 1203 & 37,75 \\
América Latina* & 290 & 34,52 & 138 & 16,43 & 277 & 32,98 & 135 & 16,07 & 840 & 26,36 \\
EUA e Canadá & 161 & 53,85 & 31 & 10,37 & 82 & 27,42 & 25 & 8,36 & 299 & 9,38 \\
Europa & 183 & 50,00 & 38 & 10,38 & 96 & 26,23 & 49 & 13,39 & 366 & 11,48 \\
Ásia & 157 & 54,33 & 22 & 7,61 & 61 & 21,11 & 49 & 16,96 & 289 & 9,07 \\
África e Oceania & 95 & 50,00 & 18 & 9,47 & 54 & 28,42 & 23 & 12,11 & 190 & 5,96 \\
Total & 1295 & 40,6 & 489 & 15,3 & 957 & 30 & 446 & 14 & 3187 & 100 \\
\hline
\end{tabular}

Nota: (*) Exceto países do Mercosul.

Fonte: Elaboração própria com base nos dados da Endei (2014).

Assim, a exportação para os países desenvolvidos requer pouco esforço em termos de inovação tecnológica e novos produtos, esforço que requer ou é favoravelmente potencializado pela cooperação com especialistas e poderia estar baseado em outros ativos estratégicos, como menores custos, manufaturas baseadas em recursos naturais, entre outros.

Para finalizar, cabe apresentar os efeitos marginais das variáveis consideradas significativas para explicar o tamanho da rede de conhecimento especializado formado pelas empresas argentinas, utilizando, para isto, o Modelo 4. Os efeitos marginais mostram quanto a probabilidade condicional da variável de resultado muda quando se altera o valor de uma variável independente, mantendo todas as outras variáveis constantes.

$\mathrm{Na}$ Tabela 4, são apresentadas as probabilidades de uma empresa possuir determinado número de vínculos com FCE devido a uma variação marginal, ou sua mudança discreta no caso de variáveis dicotômicas, nos valores das variáveis explicativas. No caso analisado, todas as variáveis significativas até o nível de $10 \%$ possuem probabili- 
dades negativas no caso de uma variação positiva, ou quando a dummie é verdadeira ${ }^{13}$, para o caso de não ter nenhum tipo de vínculo, sendo positivas para os demais casos, com probabilidades menores a cada número de vínculos superior. A exceção ocorre no caso das empresas que exportam para os EUA e Canadá, cujas empresas exportadoras têm uma probabilidade elevada em 0,1 (ou 10\%) de não ter nenhum tipo de vínculo e probabilidades negativas de ter um ou mais tipos de vínculos.

\section{Tabela 4 - Efeitos marginais estimados para o Modelo 4 -} apenas variáveis com nível de significância de até $10 \%$

\begin{tabular}{|c|c|c|c|c|}
\hline Variável & $\operatorname{Pr}($ Rede $=0)$ & $\operatorname{Pr}($ Rede $=1)$ & $\operatorname{Pr}(\operatorname{Rede}=2)$ & $\operatorname{Pr}(\operatorname{Rede}=3)$ \\
\hline Prop_engenheiros & $-0,566$ & 0,326 & 0,189 & 0,050 \\
\hline Prop_outros & $-0,161$ & 0,923 & 0,054 & 0,014 \\
\hline Ln_gasto_inovação & $-0,008$ & 0,005 & 0,003 & 0,001 \\
\hline Tamanho_empresa & $-0,077$ & 0,045 & 0,026 & 0,007 \\
\hline PeD_contínua & $-0,098$ & 0,055 & 0,034 & 0,009 \\
\hline Inovação_radical & $-0,155$ & 0,077 & 0,058 & 0,020 \\
\hline Fontes_informação & $-0,041$ & 0,024 & 0,014 & 0,004 \\
\hline Coop_inovação & $-0,161$ & 0,078 & 0,061 & 0,021 \\
\hline Aprend_inovação & $-0,161$ & 0,078 & 0,062 & 0,021 \\
\hline Clientes_Mercosul & $-0,069$ & 0,038 & 0,024 & 0,007 \\
\hline Clientes_AL & $-0,059$ & 0,033 & 0,020 & 0,006 \\
\hline Clientes_EUACan & 0,099 & $-0,062$ & $-0,030$ & $-0,007$ \\
\hline Clientes_Asia & $-0,105$ & 0,055 & 0,038 & 0,011 \\
\hline
\end{tabular}

FonteElaboração própria com base nos dados da Endei (2014).

O caso mais significativo, observado na Tabela 4, ocorre com a variável proporção de engenheiros na empresa, cuja variação marginal nessa proporção tende a reduzir em aproximadamente $0,57(57 \%)$ as chances dessa empresa não possuir nenhum tipo de vínculo com FCE e eleva em aproximadamente 0,33 (33\%) a probabilidade de ela ter pelo menos um tipo de vínculo. Da mesma forma, empresas que geraram inovações radicais e que possuem capital internacional com elos com sua matriz ou outras empresas do grupo também tendem a ter maiores redes de conhecimento especializado.

${ }_{13}$ Considerando aqui que verdadeira recebe valor igual a 1. 


\section{CONSIDERAÇÕES FINAIS}

$\mathrm{Na}$ economia moderna, caracterizada por um acirramento da concorrência entre empresas que atuam globalmente, o conhecimento é um recurso estratégico, e o aprendizado, o processo fundamental para a sustentação das competitividades. A formação de redes de fornecedores especializados representa um indício da eficácia do sistema de inovação, por remeter a conformação de laços de aprendizado capazes de fazer fluir conhecimentos de agentes dotados de competências críticas. $\mathrm{O}$ artigo investigou os fatores associados ao engajamento das empresas argentinas nesse tipo de rede, por meio de um modelo probit ordenado, cuja ordenação reflete a intensidade do engajamento das empresas, considerando o número de interações com universidades, centros tecnológicos e consultores. Utilizou-se como fonte os microdados da survey "Encuesta Nacional de Dinámica de Empleo e Innovación” (ENDEI), desenvolvida pelo Ministerio de Trabajo, Empleo y Seguridad Social (MTEySS) em parceria com o Ministerio de Ciencia, Tecnología e Innovación Productiva da Argentina e com o BID.

Os resultados sugerem fortemente que as causas da formação das redes com FCE residem nas diferentes atitudes inovadoras das empresas. A adoção de modelos mais abertos de inovação, o nível de suas capacidades de absorção e o engajamento no desenvolvimento de inovações de alto grau (radicais), são aspectos já verificados em Tether e Tajar (2008) e confirmados aqui para a indústria argentina. Importante notar que a formação de redes via capacidade de absorção foi revelada não apenas pela presença de pessoal dedicado full time a atividades de P\&D, mas também pela qualificação superior de seus trabalhadores e via outros esforços de inovação. Há muito sabe-se que atividades inovativas são muito mais do que $\mathrm{P} \& \mathrm{D}$, dado que podem envolver esforços à busca de soluções em várias etapas dos diferentes processos de inovação. Em outras palavras, a geração e difusão de conhecimentos que pode ajudar a sustentar a competitividade da firma e, consequentemente, da rede local, pode não estar assentada só em atividades de P\&D. Isso é especialmente relevante para países em desenvolvimento onde as atividades de P\&D são restritas, o que, de acordo com os resultados, não significa restrita intensidade de conhecimentos.

Nessa mesma linha, o estudo mostrou que empresas multinacionais não podem ser resumidas a comportamentos genéricos, como os que abreviam suas ações a meras atividades de produção. Destacou-se que quanto mais alto o nível de sofisticação das atividades de aprendizado tecnológico que ligaram a subsidiária à matriz, maior tende a ser a probabilidade de adensamento das relações da subsidiária com a estrutura local de conhecimentos.

O trabalho mostrou ainda que estar exposto ao mercado externo via exportações é também aspecto relevante à formação das redes. Por outro lado, a expectativa de que a inserção em mercados externos mais sofisticados pudesse induzir à busca de informações de universidades, centros tecnológicos e consultores não foi confirmada. Não 
obstante, a análise mais detalhada desse aspecto permitiu identificar a intensidade tecnológica setorial da empresa exportadora como elemento relevante à formação das redes. O setor importa! E, na Argentina, é o setor farmacêutico que tem revelado melhor desempenho inovador. O fato das capacitações terem sido objeto de política públicas de cunho não convencional (não reconhecimento de patentes, por exemplo) reforçam a noção de que políticas devem ser desenhadas para institucionalizar a capacidade de geração e difusão de inovação no SNI.

\section{REFERÊNCIAS}

AGUIAR, D; ARISTIMUÑO, F.; MAGRINI, N. El rol del Banco Interamericano de Desarrollo (BID) en la re-configuración de las instituciones y políticas de fomento a la ciencia, la tecnología y la innovación de la Argentina (1993-1999). Revista Iberoamericana de Ciencia, Tecnología y Sociedad, v. 10, n. 9, p. 11-40, 2015.

ALVAREZ, I.; MARIN, R.; FONFRÍA, A. The role of networking in the competitiveness of firms. Technological Forecasting \& Social Change, v. 76, p. 401-421, 2009.

ARIFFIN, N.; BELL, M. Firms, politics and political Economy. Industrial technology development in Malaysia. Industry and firm studies. London, Chapter 7, p. 150-190. In: SUNDARAM, J. K.; FELKER, G.; RASIAH, R. (Eds.). Industrial technology development in Malaysia: industry and firm studies. Psychology Press, 1999.

BLALOCK, G.; GERTLER, P. J. Learning from exporting revisited in a less developed setting. Journal of Development Economics, v. 75, n. 2, p. 397-416, 2004.

BRITO, J. “Cooperação para a Inovação”. In: RAPINI, M. S.; SILVA, L. A. ALBUQUERQUE, E.M. (Orgs.). Economia da Ciência, Tecnologia e Inovação - fundamentos teóricos e a economia global. Curitiba: Editora Prismas, 2017.

CALOGHIROU, Y.; KASTELLI, I.; TSAKANIKAS, A. Internal capabilities and external knowledge sources: complements or substitutes for innovative performance? Technovation, v. 24, n. 1, p. 29-39, 2004.

CASSIOLATO, J. E.; ZUCOLOTO, G.; TAVARES, J. M. H. "Empresas transnacionais e desenvolvimento tecnológico brasileiro: uma análise a partir das contribuições de François Chesnais". In: CASSIOLATO, J. E.; MATOS, M. P. M.; LASTRES, H. M. M. (Eds.). Desenvolvimento e mundialização: o Brasil e o pensamento de François Chesnais. Rio de Janeiro: E-papers, 2014, p. 177-212.

CHESBROUGH, H. W. Open innovation: The new imperative for creating and profiting from technology. Boston, MA: Harvard Business Press, 2006.

CLAUSEN, T. H. External knowledge sourcing from innovation cooperation and the role of absorptive capacity: empirical evidence from Norway and Sweden. Technology Analysis and Strategic Management, v. 25, n. 1, p. 57-70, 2013.

DOLOREX, D.; SHEARMUR, R. Innovation strategies: are knowledge-intensive business services just another source of information? Industry and Innovation, v. 20, n. 8, 2013. 
FERNANDES, A M.; ISGUT, A E. Learning-by-exporting effects: are they for real? Emerging Markets Finance and Trade, v. 51, n. 1, p. 65-89, 2015.

FORÉS, B; CAMISÓN, C. Does incremental and radical innovation performance depend on different types of knowledge accumulation capabilities and organizational size? Journal of Business Research, v. 69, n. 2, p. 831-848, 2016.

GIROUD, A.; JINDRA, B.; MAREK, P. Heterogeneous FDI in transition economies-A novel approach to assess the developmental impact of backward linkages. World Development, v. 40, n. 11, p. 2206-2220, 2012.

GIROUD, A.; HA, Y. J.; YAMIN, M. Foreign subsidiaries' internal and external R\&D cooperation in South Korea: Explanatory factors and interaction. Asian Business \& Management, v. 13, n. 3, p. 227-256, 2014.

GORDON, A. Políticas e instrumentos en ciencia, tecnología e innovación. Un panorama sobre los desarrollos recientes en América Latina. Quilmes: Políticas CTI, 2011. Disponível em: $<$ http://www.politicascti.net/index.php?option $=$ com_docman $\&$ task $=$ doc_ view\&gid=50\&Itemid=74\&lang=es $>$.

GOMES, R. A internacionalização das atividades tecnológicas pelas empresas transnacionais: elementos de organização industrial da economia da inovação. Tese (Doutorado em Economia) - Instituto de Economia, Universidade Estadual de Campinas, Campinas, 2003.

GREENE, W. H., HENSHER, D. A. Modeling ordered choices: a primer. Cambridge, MA: Cambridge University Press, 2010.

GUINET, J.; BACKER, K. The internationalization of business R\&D: evidence, impact and implications. Paris: OECD, 2008.

HAUKNES, J. Knowledge intensive services - what their role? Paris: OECD Business and Industry Policy Forum, 1998.

HERTOG den P. Knowledge-intensive business services as co-producers of innovation. International Journal of Innovation Management, v. 4, n. 4, p. 491-528, 2000.

INCE, H.; IMAMOGLUA. S. Z.; TURKCANA, H. The effect of technological innovation capabilities and absorptive capacity on firm innovativeness: a conceptual framework. Social and Behavioral Sciences, v. 235, p. 764-770, 2016.

LANDRY, R.; AMARA, N.; LAMARI, M. Does social capital determine innovation? To what extent? Technological Forecasting and Social Change, v. 69, n. 7, p. 681-701, 2002.

LAURSEN, K.; SALTER, A. Open for innovation: the role of openness in explaining innovation performance among UK manufacturing firms.Strategic Management Journal, v. 27, n. 2, p. 131-150, 2006.

LAURSEN, K.; SALTER, A. Searching high and low: what types of firms use universities as a source of innovation? Research policy,v. 33, n. 8, p. 1201-1215, 2004.

LAURSEN, K; SALTER, A. J. The paradox of openness: appropriability, external search and collaboration. Research Policy, v. 43, n. 5, p. 867-878, 2014.

LAURSEN, K. Keep searching and you'll find: what do we know about variety creation through firms' search activities for innovation? Industrial and Corporate Change, v. 21, n. 5, p. 11811220, 2012. 
MARIN, A; BELL, M. Technology spillovers from foreign direct investment (FDI): the active role of MNC subsidiaries in Argentina in the 1990s. The Journal of Development Studies, v. 42, n. 4, p. 678-697, 2006.

MARIN, A; SASIDHARAN, S. Heterogeneous MNC subsidiaries and technological spillovers: Explaining positive and negative effects in India. Research Policy, v. 39, n. 9, p. 1227-1241, 2010.

MILES, I. et al. Knowledge-intensive business services: users, carriers and sources of innovation. European Innovation Monitoring System (EIMS) Reports, 1995.

MOLDOVAN, P.; GORDON, A.; Di MARZO, E. “Estrutura científica y perfil tecnoprodutivo de la Argentina”. Cap. 1. In: ANGELELLI, P. et al. Investigación científica e innovación tecnológica en Argentina: Impacto de los fondos de la Agencia Nacional de Promoción Científica y Tecnológica.Bernal, Província de Buenos Aires, 2011.

OCDE - ORGANIZAÇÃO PARA A COOPERAÇÃO E O DESENVOLVIMENTO ECONÔMICO. Science, Technology and Industry Scoreboard. Paris: OCDE, 2003.

QIU, S; LIU, X; GAO, T. Do emerging countries prefer local knowledge or distant knowledge? Spillover effect of university collaborations on local firms. Research Policy, v. 46, n. 7, P. 12991311, 2017.

REDDY, P. The globalization of corporate R\&D: Implications for Innovation Systems in Host Countries. London: Routledge, 2002.

TETHER, B. S.; TAJAR, A. Beyond industry-university links: Sourcing knowledge for innovation from consultants, private research organisations and the public science-base.Research Policy, v. 37, n. 6, p. 1079-1095, 2008.

TÖDLING, F.; LEHNER,P.; KAUFFMAN, A. Do different types of innovation rely on specific kinds of knowledge interactions? Technovation, v. 29, p. 59-71, 2009.

UNCTAD/ITE/IIA. Globalization of R\&D and developing countries - Part IV. United Nations, New York/Geneva, Mimeo, 2006.

VEGA-JURADO, J. V. et al. The effect of external and internal factors on firms'product innovation. Research Policy, v. 37, p. 616-632, 2008.

ZHENG, W. A social capital perspective of innovation from individuals to nations: where is empirical literature directing us? International Journal of Management Reviews, v. 12, n. 2, p. 151-183, 2010.

ZUCOLOTO, G. F. Desenvolvimento tecnológico por origem de capital no Brasil: P\&D, patentes e incentivos públicos. Tese de Doutorado. Tese (Doutorado em Economia) - Instituto de Economia, Universidade Federal do Rio de Janeiro, Rio de Janeiro, 2009. 


\section{ANEXO 1 - Distribuição da amostra por setor de atividade}

\section{Tabela A.1 - Identificação do setor de atividade das empresas e distribuição da amostra por estrato.}

\begin{tabular}{|c|c|c|c|c|c|c|c|c|}
\hline Sigla & $\begin{array}{c}\text { Setor de atividade } \\
\text { (Intensidade tecnológica) }\end{array}$ & $\begin{array}{c}\text { N. de } \\
\text { empresas } \\
\text { neste } \\
\text { setor }\end{array}$ & $\begin{array}{c}\text { Participação } \\
\text { no total das } \\
\text { empresas } \\
(\%)\end{array}$ & \multicolumn{4}{|c|}{$\begin{array}{l}\text { Número de empresas } \\
\text { por tamanho da rede }\end{array}$} & $\begin{array}{c}\text { Tamanho } \\
\text { médio da } \\
\text { rede desse } \\
\text { setor }\end{array}$ \\
\hline S_A15 & Alimentos (BT) & 336 & 9,10 & 139 & 89 & 58 & 50 & 1,06 \\
\hline S_A17 & Produtos têxteis (BT) & 198 & 5,36 & 104 & 36 & 34 & 24 & 0,89 \\
\hline S_A18 & Confecções (BT) & 146 & 3,96 & 64 & 38 & 24 & 20 & 1,00 \\
\hline S_A19 & Couro (BT) & 135 & 3,66 & 81 & 23 & 18 & 13 & 0,73 \\
\hline S_A20 & Madeira (BT) & 131 & 3,55 & 58 & 33 & 23 & 17 & 0,99 \\
\hline S_A21 & Papel (BT) & 135 & 3,66 & 73 & 27 & 29 & 6 & 0,76 \\
\hline S_A22 & Edição (BT) & 136 & 3,68 & 77 & 33 & 18 & 8 & 0,68 \\
\hline S_A24 & Produtos químicos (MAT) & 181 & 4,90 & 95 & 38 & 31 & 17 & 0,83 \\
\hline S_A25 & $\begin{array}{l}\text { Produtos de borracha e plástico } \\
\text { (MBT) }\end{array}$ & 192 & 5,20 & 93 & 47 & 42 & 10 & 0,84 \\
\hline S_A26 & $\begin{array}{l}\text { Outros minerais não metálicos } \\
\text { (MBT) }\end{array}$ & 130 & 3,52 & 65 & 30 & 30 & 5 & 0,81 \\
\hline S_A27 & Metais comuns (MBT) & 129 & 3,49 & 66 & 39 & 19 & 5 & 0,71 \\
\hline S_A28 & $\begin{array}{l}\text { Outros produtos de metal } \\
\text { (MBT) }\end{array}$ & 228 & 6,18 & 121 & 63 & 31 & 13 & 0,72 \\
\hline S_A29 & $\begin{array}{l}\text { Máquinas e equipamentos } \\
\text { (MAT) }\end{array}$ & 121 & 3,28 & 94 & 21 & 3 & 3 & 0,30 \\
\hline S_A33 & Instrumentos médicos (AT) & 79 & 2,14 & 56 & 19 & 3 & 1 & 0,35 \\
\hline S_A35 & $\begin{array}{l}\text { Outros equipamentos de } \\
\text { transporte (MAT) }\end{array}$ & 74 & 2,00 & 57 & 13 & 4 & 0 & 0,28 \\
\hline S_A36 & Móveis (BT) & 133 & 3,60 & 102 & 23 & 7 & 1 & 0,30 \\
\hline S_A299 & $\begin{array}{l}\text { Máquinas-ferramentas em geral } \\
\text { (MAT) }\end{array}$ & 124 & 3,36 & 89 & 27 & 6 & 2 & 0,36 \\
\hline S_A1511 & Frigoríficos $(\mathrm{BT})$ & 175 & 4,74 & 123 & 33 & 11 & 8 & 0,45 \\
\hline S_A1520 & Produtos lácteos (BT) & 122 & 3,31 & 89 & 26 & 5 & 2 & 0,34 \\
\hline S_A1552 & $\begin{array}{l}\text { Vinhos e outras bebidas } \\
\text { fermentadas (BT) }\end{array}$ & 101 & 2,74 & 78 & 18 & 4 & 1 & 0,29 \\
\hline S_A2423 & Farmacêuticas (AT) & 136 & 3,68 & 101 & 21 & 11 & 3 & 0,38 \\
\hline S_A2921 & $\begin{array}{c}\text { Maquinaria agropecuária e } \\
\text { florestal (MAT) }\end{array}$ & 76 & 2,06 & 61 & 9 & 6 & 0 & 0,28 \\
\hline
\end{tabular}


BITTENCOURT, P. F.; SIGNOR, D.; CATELA, E. Y. S.; RAPINI, M. S. Mais do que relação universidade empresa: uma análise das fontes de conhecimento...

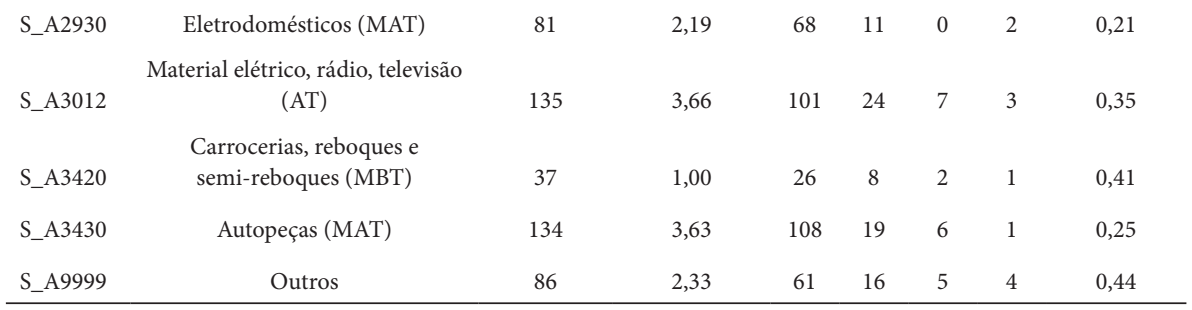

Fonte: Elaborado pelos autores com base nos dados da Endei (2014). 